fournal of Medical Genetics (1975). 12, 243.

\title{
Development of dermal ridges in the fetus*
}

\author{
M. OKAJIMA \\ From the Department of Forensic Medicine, Tokyo Medical and Dental University, Bunkyo-ku, Tokyo, fapan
}

Summary. This paper describes a new technique to inspect dermal ridges on the dermal surface instead of the epidermal surface. The dermal surface was exposed by chemical treatment and stained with toluidine blue. Dermal ridges are observable by the metachromatic effect of the reagent, which might suggest a close relationship between morphological characteristics and quantitative variations of biochemical components in the connective tissue. Dermatoglyphic features were recognized in fetuses from the 14th gestational week. Morphogenesis of dermal components-that is, grooves, primary and secondary dermal ridges, furrows, papillae, and sweat ducts-was examined at various gestational stages. The general law in the developmental sequence of the ridges in different volar areas was also confirmed.

Many studies on the dermal ridges have been reported from the standpoint of developmental anatomy. Most of them are concerned with the histological survey of fetuses at various developmental stages. It is, however, not easy with this method to describe morphogenesis of the dermal ridges precisely. A three-dimensional conception of the subject is also required for this purpose.

Hale (1952) reconstructed the three-dimensional structure of the under-surface of the epidermis for various fetal stages with stained serial histological sections and illustrated the morphogenesis of the dermo-epidermal junction. His study contributes much to the understanding of ridge formation, but this is a time-consuming method and gives no information about dermatoglyphic patterns.

Simple methods of dermatoglyphic examination are printing with ink, casting, and direct inspection of the epidermal surface. Prints are usually not obtainable from fetuses because the epidermal ridges are too fine and not sufficiently elevated. In earlier fetuses, the epidermal surface is flat, and the ridges are distinguished as the refraction of light through the fairly transparent epidermal tissue rather than the elevation of the epidermis. Therefore, in fetuses the direct inspection with a stereo-

Received 17 September 1974.

- Presented in part at the Dermatoglyphics Session of the IX International Congress of Anthropological and Ethnological Sciences, Trent in August 1973 and the 5th Congress of the International Primatological Society, Nagoya in August 1974. microscope is better than trying to obtain prints. Miller (1968) inspected dermatoglyphics of human fetuses directly and classified dermal patterns in specimens from the latter half of gestation with no special treatment or application of a depilatory cream.

Another approach to the inspection of dermal ridges is a maceration technique. The epidermis can be abraded from the dermis by various procedures and sometimes incidentally during decomposition or the preservation of cadavers. Blaschko (1887) demonstrated ridge arrangements on the under-surface of epidermis, treated with a weak alcohol, abraded from the finger tip of a fetus in the fourth month. A systematic investigation of the under-surface of abraded epidermis was made by Fleischhauer and Horstmann (1951/1952) for fetuses of various crown-rump measurements. The epidermis was abraded with $1 \%$ acetic acid and the dry specimen was produced by treatment with turpentine. In this study, morphological differentiation of the dermo-epidermal junction was clearly seen. Specimens used for this technique must be fresh, and those fixed in formalin or alcohol are no use. In these specimens, an inspection of the whole surface, which is essential for the dermatoglyphic examination, may be disturbed by contraction and wrinkling of the epidermal tissue during treatment.

On the other hand, Chacko and Vaidya (1968) observed the surface of the dermis using macerated volar skins from human newborns and adults and 
primate and subprimate mammalian species. They classified the morphological characteristics of dermal surface into three types according to the relative depth of grooves and furrows, and pointed out variations in species, volar areas, and ages. Details of the maceration technique, however, are not presented in this paper.

As is now well known, analysis of dermatoglyphic patterns is widely used as an important tool for the diagnosis of congenital malformations (Holt, 1968; Penrose, 1968a; Holt, 1973; Miller, 1973). However, it has not been applied effectively in systematic studies of fetal malformations (Poland and Lowry, 1974), because of the inadequate methods at present available for the study of dermatoglyphic patterns in the fetus. The maceration of the skin which can occur in spontaneous abortuses may also discourage attempts to examine the dermatoglyphs.

The present paper is concerned with a technique which has made it possible to inspect the dermatoglyphic features on the whole volar surface in human fetuses from the early stages of ridge formation.

\section{Material}

Volar specimens were obtained from 21 human fetuses. These fetuses were obtained at induced abortions, all performed by dilatation and curettage; they were at various gestational ages and thought to be normal. In 12 cases, only hands and feet were available. For most of the specimens dates of the last menstrual period and abortion were available, but for a few other specimens details of gestational age only were given. These specimens were all fixed by $10 \%$ formalin and examined within a few months of the induced abortion.

No historical records about the length of gestation were available for the other nine fetuses, but the crownrump length was measured. These specimens had been preserved in formalin over 10 years. The length of palm and sole was measured on every specimen; the fingers and toes being excluded from this measurement. In addition, volar skins were obtained from several human adults for this study.

\section{Method}

Specimens fixed in formalin were washed in water for a short time. Hands and feet were cut off from the body to make handling easier. The specimen, as a whole hand or foot or a piece of skin, was incubated in 3\% potassium hydroxide solution for 4 to $8 \mathrm{~h}$ at $28^{\circ} \mathrm{C}$. It was then washed in running water for anything up to $12 \mathrm{~h}$ and kept in a large volume of $10 \%$ formalin for several days. The specimen was then brushed in water; the older fetuses with foam rubber and the younger fetuses gently with a cotton bud under a stereomicroscope. The epidermis could then be easily flaked off from the dermo-epidermal junction and the surface of the dermis exposed.
If the term of preservation in formalin is not sufficient after the treatment by alkaline solution, the epidermis cannot be removed easily. When a fetus is young, the dermal tissue is tender and can be damaged by this manipulation. Therefore, it is recommended in such cases that the specimen be stained with toluidine blue solution, as stated below, before and, if necessary, during the brushing to make it easier to distinguish the epidermis from the underlying dermis. As the fingers of older fetuses are bent thus hindering the observation, the hand and fingers were held in extension with a thread on a rubber or plastic plate.

For the inspection, the dermis is stained with $0.05 \%$ toluidine blue solution for about $30 \mathrm{~s}$. The reagent was tested at pH 5.0 and 6.0, in dilution in distilled water or in $1 \%$ borax solution. As the precise $\mathrm{pH}$ did not appear to matter, the solution made up with distilled water was usually used.

The stained specimen was set in water and inspected and photographed with a stereomicroscope. The position of the specimen must be manually controlled during the examination because of the curvature of the dermal surface, which is generally marked in fetuses, and it is often impossible to photograph a whole pattern in focus.

Toluidine blue gives an excellent metachromatic effect on the dermis. If a specimen fades during examination, it can be restained. Specimens can be reexamined when they are preserved in formalin.

\section{Structure of dermal surface and terminolog}

As Fig. 1 shows, the ridged skin is constructed of epidermis and dermis. According to the nomenclature proposed by Penrose (1968b), the surface of the dermis of normally developed individuals is composed of grooves, furrows, and papillae which follow the alignment of the epidermal ridges and furrows. The ducts of sweat glands lie in the grooves on the dermal surface. Fig. 1 was reconstructed from the literature to provide an outline of the developmental sequence of the epidermal and dermal ridges including the precursory stage where volar pads appear and regress (Cummins, 1929; Cummins and Midlo, 1943; Fleischhauer and Horstmann, 1951/1952; Hale, 1952; Mulvihill and Smith, 1969).

During the 12th and 13th weeks of gestation, undulations occur at the dermo-epidermal junction and thus the primary dermal ridges and grooves begin to differentiate. Then the summits of the primary dermal ridges begin to be subdivided into double parallel ridges-the secondary dermal ridges-by the formation of the furrow from about the 18th to 19th week. In this paper the terms 'primary' and 'secondary' dermal ridges, which were presented in the report by Mulvihill and Smith (1969) are used. In the seventh month, differentiation and development of dermal papillae take place on the secondary dermal ridges. The dermal papillae which are originally arranged in double rows under a corresponding epidermal ridge, change conspicuously in number, shape, size, and arrangement throughout fetal life and continue to change even after birth. 


\begin{tabular}{ccccccc} 
C.R. (mm) 20 & 40 & 60 & 100 & 150 & 200 \\
\hline Age $(\mathrm{wk}) 6$ & 10 & 12 & 16 & 20 & 24 & 28 \\
\hline
\end{tabular}
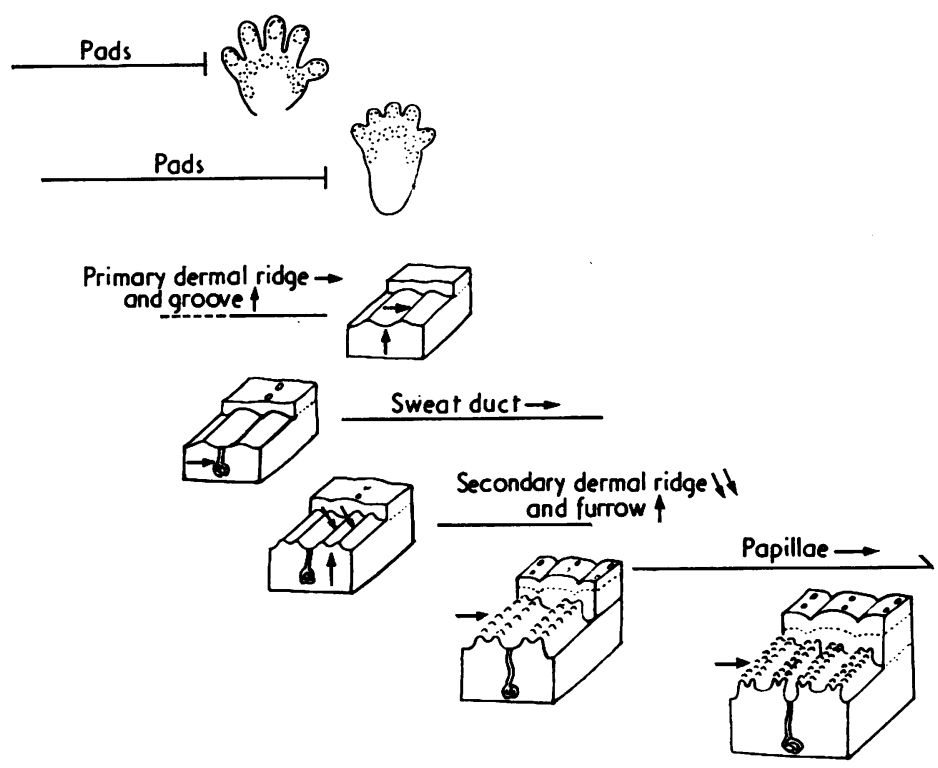

FIG. 1. Morphogenesis of dermal ridges diagrammatically reconstructed from the literature.

\section{Results}

Primary dermal ridges. The primary dermal ridges are revealed in blue to blue-violet tones with toluidine blue staining. However, the grooves are not stained with the reagent.

The gestational age of the youngest fetus (fetus 1) in the present series was 12 weeks and 6 days and one hand and one foot were examined (Table 1). The palm length was $5.5 \mathrm{~mm}$ and fairly reduced pads were still recognizable on the digital apices. The sole was $8.3 \mathrm{~mm}$ in the length and the pads on the digital apices are still relatively large. The epidermis of both specimens were stained with toluidine blue solution before examination and

TABLE I

DEVELOPMENT OF PRIMARY DERMAL RIDGES

\begin{tabular}{|c|c|c|c|c|c|c|c|c|c|c|}
\hline & \multicolumn{10}{|c|}{ Fetus } \\
\hline & 1 & 2 & 3 & 4 & 5 & 6 & 7 & 8 & 9 & 10 \\
\hline $\begin{array}{l}\text { Gestational age } \\
\text { Week } \\
\text { Day }\end{array}$ & $\begin{array}{r}12 \\
6\end{array}$ & $\begin{array}{r}13 \\
2\end{array}$ & $\begin{array}{r}13 \\
3\end{array}$ & $\begin{array}{r}13 \\
6\end{array}$ & 14th & $\begin{array}{l}15 \\
4\end{array}$ & & $\begin{array}{c}16 \\
5\end{array}$ & & \\
\hline $\begin{array}{l}\text { Crown-rump length } \\
\text { (mm) }\end{array}$ & & & & & & & 100 & & 135 & 140 \\
\hline $\begin{array}{l}\text { Palm length (mm) } \\
\text { Finger apex } \\
\text { Phalanx } \\
\text { Palm }\end{array}$ & $\begin{array}{l}5.5 \\
= \\
=\end{array}$ & & $\begin{array}{c}7.3 \\
+ \\
(+) \\
(+)\end{array}$ & $\begin{array}{c}7.0 \\
+ \\
+\end{array}$ & $\begin{array}{l}7.5 \\
(+) \\
(+) \\
(+)\end{array}$ & $\begin{array}{l}9.5 \\
++ \\
+ \\
+\end{array}$ & $\begin{array}{l}11.5 \\
++ \\
++ \\
++\end{array}$ & $\begin{array}{l}11.5 \\
++ \\
++ \\
++\end{array}$ & & $\begin{array}{l}12.3 \\
++ \\
++ \\
++\end{array}$ \\
\hline $\begin{array}{l}\text { Sole length }(\mathrm{mm}) \\
\text { Toe apex } \\
\text { Sole }\end{array}$ & $\begin{array}{l}8.3 \\
-\end{array}$ & $\begin{array}{l}7.4 \\
-\end{array}$ & $\begin{array}{l}11.7 \\
(+) \\
(+)\end{array}$ & $\begin{array}{l}11.5 \\
(+) \\
(+)\end{array}$ & $\begin{array}{l}10.7 \\
(+) \\
(+)\end{array}$ & $\begin{array}{c}16.5 \\
+ \\
+\end{array}$ & $\begin{array}{l}18.8 \\
++ \\
++\end{array}$ & $\begin{array}{l}19.5 \\
++ \\
++\end{array}$ & $\begin{array}{l}22.0 \\
++ \\
++\end{array}$ & \\
\hline
\end{tabular}

- No ridge formation.

(+) Ridge formation is positive, but ridges are not distinguishable from each other.

+ Ridges are sharp; ridge counting is feasible.

++ Ridges are sharp; minutia types are discernible. 
brushed off with a cotton bud under stereomicroscopic vision. During this procedure staining was repeated, but no ridge formation could be confirmed on the whole surface of the volar skin. In fetus 2 , only one foot was examined in the same way. Its length is $7.4 \mathrm{~mm}$ and somewhat smaller than the fetus 1 . No ridges were observed.
One hand (palm length $7.3 \mathrm{~mm}$ ) and one foot $\stackrel{\frac{1}{\infty}}{\Omega}$ (sole length $11.7 \mathrm{~mm}$ ) from fetus 3 (13 weeks and 8 3 days) were examined. Dermatoglyphic patterns could be clearly determined on the whole volar surface, though the ridges were not yet sharply separated from one another except on the finger apices. On the finger apices, the ridges were dis-

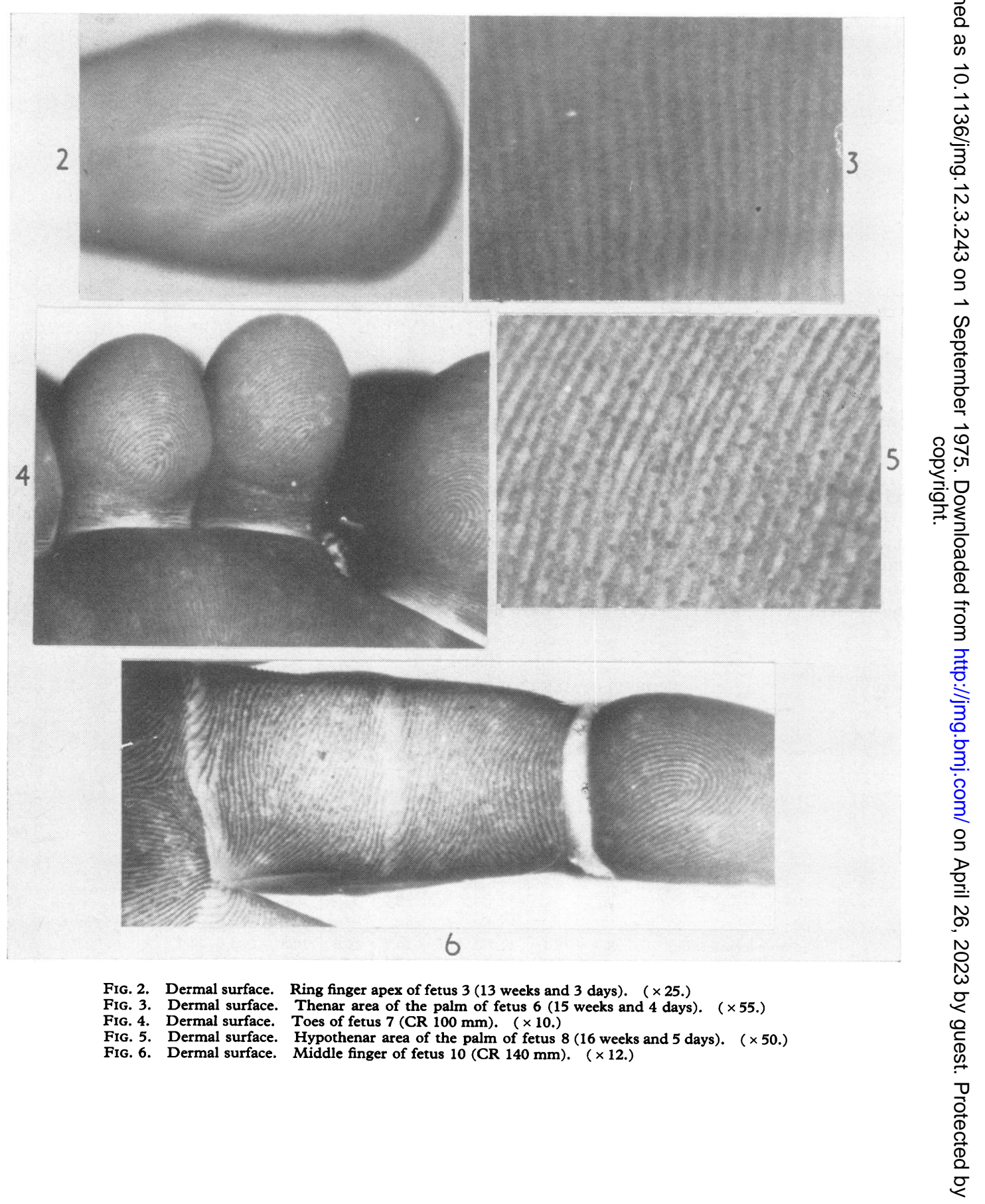


tinctive enough to be counted (Fig. 2) and their development anticipated the other volar areas in the hand and foot. The ridges on the toe apices were also at a somewhat earlier period of development than the sole. Similar findings were obtained in fetuses 4 and 5 which were both in the 14th gestational week. In fetus 4 , the primary dermal ridges seemed to be, to some extent, sharper in the calcar area than the other sole areas.

In fetus 6 ( 15 weeks and 4 days) the primary dermal ridges on the finger apices were sharp enough to be counted and minutia types are distinguishable. In other volar areas, however, development of ridges differs from one part to another but all the ridges are generally discernible (Fig. 3 ).

Primary dermal ridges and grooves were well developed in fetuses 7 and 8 . The former was $100 \mathrm{~mm}$ in the CR length and the latter was 16 weeks and 5 days. Both fetuses presented similar values in the palm and sole length, about $11.5 \mathrm{~mm}$ and $19 \mathrm{~mm}$, respectively. The other findings were also similar, and in each fetus primary dermal ridges and details of minutia forms can be clearly identified except for the hypothenar and proximal thenar areas of the soles where exact ridge counting was not possible (Figs. 4 and 5).

In the hands and feet of fetuses, 9, 10, and 11, which are older than the above specimens, welldeveloped primary dermal ridges cover the whole volar surface (Fig. 6).

Secondary dermal ridges. In a surface view of the dermis, the secondary dermal ridge is stained with toluidine blue in a violet tone. The furrow is recognizable as a blue violet to light blue line between the two related secondary dermal ridges. On staining the groove remains rather indistinct. According to the survey of the literature, the secondary dermal ridges begin to differentiate at the end of the fifth gestational month.

In the present series, the secondary dermal ridges first appeared partially in fetus 12 (19 weeks and 2 days) and fetus 13 (CR length is $154 \mathrm{~mm}$ ). Though the differentiation of this trait increases with fetal age, its completion on the whole volar surface could not be confirmed in fetuses $14,15,16$, and 17; all approximately in the sixth gestational month (Table II). This phenomenon seems to be caused by the relatively slowly developing process of the trait itself. But it is the author's impression, however, that there is another possibility; namely, that the ability of the dermis to fix toluidine blue is somewhat reduced during this period. Therefore, it was occasionally difficult to describe the real structure of the dermal surface or the ridge count exactly. This can be seen from the unclearly defined data in Table II.

Fetus 14 was reported to be in the 20th week. However, it might be suggested from the measurements of the palm and sole length and findings of the secondary dermal ridges that the real gestational age was one or two weeks later. Fig. 7 shows the dermal surface in the interdigital area of the palm of fetus 14. It is recognizable that the secondary dermal ridges and furrows are differentiated. In this fetus, secondary dermal ridges were observed on the whole palm except for a small part of the hypothenar area, but on the sole only on the toe

TABLE II

DEVELOPMENT OF SECONDARY DERMAL RIDGES

\begin{tabular}{|c|c|c|c|c|c|c|c|c|c|c|c|}
\hline & \multicolumn{11}{|c|}{ Fetus } \\
\hline & 9 & 10 & 11 & 12 & 13 & 14 & 15 & 16 & 17 & 18 & 19 \\
\hline $\begin{array}{l}\text { Gestational age } \\
\text { Week } \\
\text { Day }\end{array}$ & & & 18 th & $\begin{array}{r}19 \\
2\end{array}$ & & 20 th $^{*}$ & & & & & 25 th \\
\hline Crown-rump length (mm) & 135 & 140 & & & 154 & & 164 & 172 & 188 & 216 & \\
\hline $\begin{array}{l}\text { Palm length (mm) } \\
\text { Finger apex } \\
\text { Phalanx } \\
\text { Palm }\end{array}$ & & $\begin{array}{c}12.3 \\
- \\
-\end{array}$ & $\begin{array}{l}13.5 \\
- \\
-\end{array}$ & $\begin{array}{c}14.0 \\
+/- \\
-\bar{I}(+)\end{array}$ & $\begin{array}{l}15.3 \\
+1- \\
+1- \\
+1-\end{array}$ & $\begin{array}{c}17.0 \\
+ \\
+ \\
+1-\end{array}$ & $\begin{array}{c}15.5 \\
? \\
? \\
?\end{array}$ & $\begin{array}{l}16.8 \\
-1+ \\
-1+ \\
-1+\end{array}$ & $\begin{array}{l}19.5 \\
+ \\
+1- \\
+1-\end{array}$ & $\begin{array}{l}20.0 \\
++ \\
++ \\
++\end{array}$ & $\begin{array}{l}22.0 \\
++ \\
++ \\
++\end{array}$ \\
\hline $\begin{array}{l}\text { Sole length }(\mathrm{mm}) \\
\text { Toe apex } \\
\text { Sole }\end{array}$ & $\begin{array}{c}22.0 \\
- \\
-\end{array}$ & & $\begin{array}{c}23.5 \\
- \\
-\end{array}$ & $\begin{array}{c}24.0 \\
- \\
-\end{array}$ & $\begin{array}{l}27.5 \\
+1- \\
+1-\end{array}$ & $\begin{array}{l}31.0 \\
+1- \\
-1+\end{array}$ & $\begin{array}{c}30.0 \\
? \\
?\end{array}$ & $\begin{array}{l}31.5 \\
+1- \\
-1+\end{array}$ & $\begin{array}{l}35.0 \\
+ \\
+1-\end{array}$ & $\begin{array}{l}41.5 \\
++ \\
++\end{array}$ & $\begin{array}{l}42.0 \\
++ \\
++\end{array}$ \\
\hline
\end{tabular}

- Negative.

? Uncertain

$(+)$ Abortive

+ Moderately developed.

++ Developed.

* Presumably somewhat older. 


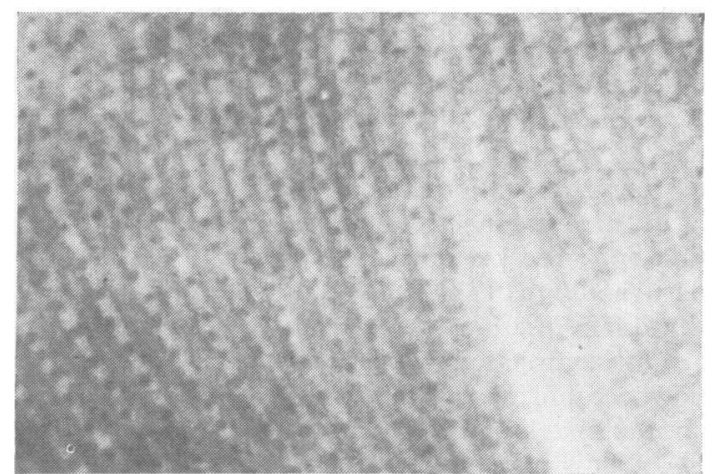

FIG. 7. Dermal surface. Interdigital area of the palm of fetus 14 (presumably in the first half of the 6th month). ( $\times 42$.

apices and in the calcar area. It was also noticeable that the differentiation apparently begins slightly earlier in radial fingers than in ulnar fingers.

In fetuses 18, 19, and 20 (over six months), formations of secondary dermal ridges and furrows are complete, but the furrows in fetus 19 are still so narrow in a small part of the hypothenar area of the sole that the double linear structure was hardly discernible.

Dermal papillae. Dermal papillae are first recognized as low bulges with colour accentuation in violet to red violet on the secondary dermal ridges.

In the present series, they appeared first in fetus 17 (CR length $188 \mathrm{~mm}$ ) as dim spots, but clearly in fetus 18 (CR length $216 \mathrm{~mm}$ ) and fetuses 19, 20, and
21 (Table III). At this stage, the colour contrast between papillae including secondary dermal ridges, furrows, and grooves is very sharp (Figs. 8 and 9).

The structure of the dermal surface, especially of papillae, changes with the age throughout fetal life and even after the birth. Fig. 10 shows the dermal surface on the finger apex of an adult. Summits of papillae are selectively stained with toluidine blue. The furrows are far broader than the grooves. Papillae are arranged here in a crowded state on both sides of the groove, though their original double row arrangement has remained. Thus the dermal papillae have changed in adults and look quite different when compared with fetal dermal papillae.

Sweat ducts. Ducts of sweat glands are one of the traits identified at the dermal surface. Sweat ducts were recognized, by this staining method, first in fetus 8 ( 16 weeks and 5 days) on the whole palmar surface and partially on the toes and hallucal area (see Fig. 5). They are stained in light blue but the number is generally low and particularly sparse on the sole. The affinity of the sweat ducts for toluidine blue and their number increase with fetal age. Usually in fetuses in the sixth gestational month, the sweat ducts stain strongly blue, in contrast with the observation that, as stated above, the other dermal elements stain rather weakly in this period. In these cases, sweat ducts are sharply delineated from the surrounding tissue and arranged in blue dotted lines (see Fig. 7). When fetuses become larger, the affinity of the sweat ducts for the reagent regresses, and they are recognized either as faint blue spots or are occasionally invisible (see Figs. 8 and 9).

TABLE III

DEVELOPMENT OF DERMAL PAPILLAE

\begin{tabular}{|c|c|c|c|c|c|c|c|c|c|}
\hline & \multicolumn{9}{|c|}{ Fetus } \\
\hline & 13 & 14 & 15 & 16 & 17 & 18 & 19 & 20 & 21 \\
\hline $\begin{array}{l}\text { Gestational age } \\
\text { Week } \\
\text { Day }\end{array}$ & & 20th* & & & & & 25 th & 30th & \\
\hline Crown-rump length (mm) & 154 & & 164 & 172 & 188 & 216 & & & 260 \\
\hline $\begin{array}{l}\text { Palm length (mm) } \\
\text { Finger apex } \\
\text { Phalanx } \\
\text { Palm } \\
\end{array}$ & $\begin{array}{c}15.3 \\
- \\
-\end{array}$ & $\begin{array}{l}17.0 \\
- \\
-\end{array}$ & $\begin{array}{c}15.5 \\
- \\
- \\
\end{array}$ & $\begin{array}{c}16.8 \\
- \\
-\end{array}$ & $\begin{array}{l}19.5 \\
(+) /- \\
(+) /- \\
-\end{array}$ & $\begin{array}{c}20.0 \\
+ \\
+ \\
+\end{array}$ & $\begin{array}{c}22.0 \\
+1+ \\
+ \\
+\end{array}$ & $\begin{array}{l}24.0 \\
++ \\
++ \\
++\end{array}$ & $\begin{array}{l}29.0 \\
++ \\
++ \\
++\end{array}$ \\
\hline $\begin{array}{l}\text { Sole length }(\mathrm{mm}) \\
\text { Toe apex } \\
\text { Sole }\end{array}$ & $\begin{array}{c}27.5 \\
- \\
-\end{array}$ & $\begin{array}{c}31.0 \\
- \\
-\end{array}$ & $\begin{array}{c}30.0 \\
- \\
-\end{array}$ & $\begin{array}{c}31.5 \\
-\end{array}$ & $\begin{array}{c}35.0 \\
-/(+) \\
-/(+)\end{array}$ & $\begin{array}{l}41.5 \\
+ \\
+\end{array}$ & $\begin{array}{l}42.0 \\
+ \\
+\end{array}$ & $\begin{array}{c}47.5 \\
++1+ \\
++1+\end{array}$ & $\begin{array}{l}58.5 \\
++ \\
++\end{array}$ \\
\hline
\end{tabular}

- Negative.

(+) Spot-like appearance.

+ Low elevation.

++ Developed.

* Presumably somewhat older. 


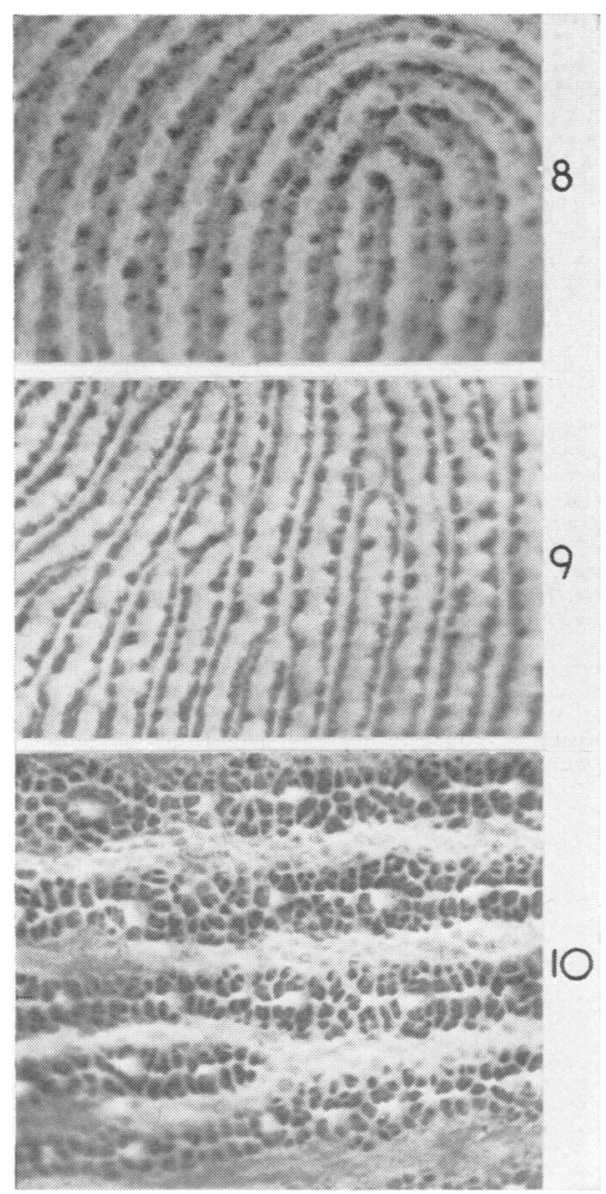

Fig. 8. Dermal surface. Index finger apex of fetus 19 (25th week). $(\times 35$.

FIG. 9. Dermal surface. Interdigital area of the palm of fetus 20 (30th week). ( $\times 30$.)

FIg. 10. Dermal surface. Finger apex of an adult. $(\times 18$.

\section{Discussion}

Despite the recent increasing importance of dermatoglyphics in human genetics, our knowledge about the development of these traits is still poor (Holt, 1970; Miller, 1973). This paper reports a new technique which allows a surface view of the fetal dermal ridges on the dermal surface instead of the usual observation of the epidermal surface. In general, the findings obtained in this study coincide with previous descriptions (Fleischhauer and Horstmann, 1951/1952; Hale, 1952; Mulvihill and Smith, 1969).
Dermatoglyphic configurations were first recognized, in this study, in fetuses in the 14th week. These configurations are displayed by stained primary dermal ridges on the dermis. This period is chronologically continued by the prior stage where volar pads regress and is considered to be most important for pattern determination. Details of the relationship between pad regression and pattern formation may be analysed in further studies conducted with the present technique.

Secondary dermal ridges, according to the literature, begin to appear approximately in the 18th or 19th week; in this study they were recognized first in the 20th week in an embryonic state. The differentiation of this trait proceeds during the sixth gestational month. From the present study it seems to be characteristic in about the sixth month, that the ability of the dermal tissue to fix toluidine blue is reduced. Though the possibility of artefact is at present not completely excluded, a histochemical meaning of this phenomenon should be studied, as well as a revision of the examination technique. Therefore, inspection of the dermal surface including ridge counting was occasionally difficult. This is relevant to the study of congenital malformations, because chromosomally abnormal fetuses which are picked up by amniocentesis are frequently therapeutically aborted in the sixth month.

Differentiation of dermal papillae takes place from the seventh gestational month. Although the fact that derma papillae may change in number, shape, and arrangement has been suggested (Blaschko, 1887; Fleischhauer and Horstmann, 1951/1952), our knowledge about the developmental events is still deficient. Therefore, a standard time-table for the development of dermal papillae should be prepared in advance for various ages, not only for the fetal period but for after the birth as well.

According to the present results, sweat ducts are stained with toluidine blue strongly in the sixth gestational month, whereas before or after this month, they are stained weakly or not at all. Previous authors (Fleischhauer and Horstmann, 1951/1952) have observed that the sweat ducts first appear in the fourth month and increase in number until the sixth month. This could not be confirmed in the present study because of the limitation of the staining effect.

The metachromasia of toluidine blue observed on the dermal surface may reflect the fact that contents of biochemical components in the ground substance in the skin connective tissue are locally different. On the other hand, the three principal glycosaminoglycans of the ground substance (hyaluronate, 
dermatan sulphate, and chondroitin 4 or 6 sulphate) change qualitatively and quantitatively primarily during fetal life, infancy, or early childhood. Very little change takes place after that (Pearse, 1968; Montagna and Parakkal, 1974). The changing effect of staining on the dermis might suggest a close relationship between the biochemical components and the conspicuous morphogenesis of this tissue. Further interpretations of the development of dermatoglyphics in the fetus using the present technique are anticipated.

The author is grateful to Professor M. Akiyoshi, Tokyo Medical and Dental University, and Professor $M$. Okudaira, Kitasato University, for helpful advice.

\section{REFERENCES}

Blaschko, A. (1887). Beiträge zur Anatomie der Oberhaut. Archiv für Mikroskopische Anatomie, 30, 495-528.

Chacko, L. W. and Vaidya, M. C. (1968). The dermal papillae and ridge patterns in human volar skin. Acta Anatomica, 70, 99-108.

Cummins, H. (1929). The topographic history of the volar pads (walking pads; Tastballen) in the human embryo. Contributions to Embryology, 20, 103-126.

Cummins, H. and Midlo, C. (1943). Finger Prints, Palms and Soles.
Blakiston, New York. (Republished in 1961 by Dover, New York.)

Fleischhauer, K. and Horstmann, E. (1951/1952). Untersuchungen über die Entwicklung des Papillarkörpers der menschlichen Palma und Planta. Zeitschrift für Zellförschung und Mikroskopische Anatomie, 36, 298-318.

Hale, A. R. (1952). Morphogenesis of volar skin in the human fetus. American fournal of Anatomy, 81, 147-181.

Holt, S. B. (1968). The Genetics of Dermal Ridges. Thomas, Springfield, Illinois.

Holt, S. B. (1970). The morphogenesis of volar skin. Developmental Medicine and Child Neurology, 12, 369-371.

Holt, S. B. (1973). The significance of dermatoglyphics in medicine. Clinica Pediatrica, 12, 471-484.

Miller, J. R. (1968). Dermal ridge patterns: Technique for their study in human fetuses. Fournal of Pediatrics, 73, 614-616.

Miller, J. R. (1973). Dermatoglyphics. Fournal of Investigative Dermatology, 60, 435-442.

Montagna, W. and Parakkal, P. F. (1974). The Structure and Function of Skin. Academic Press, New York.

Mulvihill, J. J. and Smith, D. W. (1969). The genesis of dermatoglyphics. Fournal of Pediatrics, 75, 579-589.

Pearse, A. G. E. (1968). Histochemistry, vol. 1. Little, Brown, Boston.

Penrose, L. S. (1968a). Medical significance of finger-prints and related phenomena. British Medical fournal, 2, 321-325.

Penrose, L. S. (1968b). Memorandum on dermatoglyphic nomenclature. Birth Defects Original Article Series, vol. 4, no. 3. National Foundation-March of Dimes, New York.

Poland, B. J. and Lowry, R. B. (1974). The use of spontaneous abortuses and stillbirths in genetic counselling. American fournal of Obstetrics and Gynecology, 118, 322-326. 